\title{
Research on the calculated model of Protective Relaying of considering wind power connected to the grid
}

\author{
Qing YAN ${ }^{1}$,Dongliang $N A N^{5}$,Xiaoping $F E N G^{1}$, Yuanzhen $\mathrm{YANG}^{3}$, Xiaotong

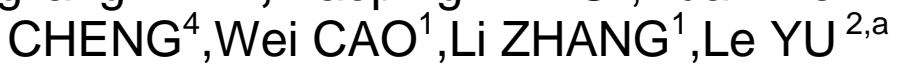 \\ ${ }^{1}$ State grid xinjiang electric power company control center, wulumuqi, China \\ 2 Join Bright Co., Ltd., Beijing , China \\ ${ }^{3}$ State grid akesu electric power supply company, akesu, China \\ ${ }^{4}$ State grid bazhou electric power supply company, bazhou, China \\ ${ }^{5}$ State grid xinjiang electric power company research institute, wulumuqi, China \\ ayule1002@yeah.net
}

Keywords: Power System Protective Relaying, Wind Power, Wind Farm equivalent impedance.

Abstract. Due to large-scale wind farms connected to the grid, so when the grid computing need to consider the impact of wind farm integrated into the power grid. Paper firstly analyzes the model individual wind turbine. Analysis of the resistance Crowbar access to wind turbine model and the number of wind turbines running impact on the positive and negative sequence impedance, obtained wind turbine positive and negative sequence impedance calculation formula in the large and small operation mode. Then according to the actual connection of wind farms, bearing in mind impact of the transformer access, wind generators and transformers series equivalent to a wind chassis variant group. Finally, to Calculate the equivalently impedance according to the actual parameters of wind farms, and to verify the accuracy of the results calculated by the fault.

\section{Introduction}

Protective relaying is the primary defense of the power grid. Faults could be efficiently and rapidly isolated to prevent the system from getting worse, and therefore, guarantee the effective and stable power transmission and usage. In recent years ${ }^{[1-3]}$, along with the energy crisis and environmental problem, new energy and distributed generation, for instance, wind farm and photovoltaic, draw much more attention than ever before. With the extensive application of these technologies, centralized connection, remote transmission and wind farm inner lines network would change the characteristics of the power system operation ${ }^{[4]}$.

\section{Single wind turbine model}

Along with the strict requirement aimed at the on-grid wind farm operation, low voltage ride through (LVRT) ability is commonly required by numbers of standards due to the continuous increase of the wind power scale and unit capacity. LVRT, refers to low voltage ride through, means that wind farms stay connected with the grid, inject reactive power and support it while the voltage dropping at the connection point until the voltage recovers to normal level. LVRT is a special functional requirement towards the situation that the on-grid wind farm stay connected during a voltage drop ${ }^{[5]}$. Double-fed induction machine (DFIG) is the most common technology that has been applied in the wind power generation due to its adjustable power factor, high efficiency, low frequency conversion capacity and limited capital investment.

Coiling asynchronous machine is the main type that used in DFIG. The stator of the generator is directly connected to the grid, and rotor to the grid with AC-DC-AC convertor. A sudden voltage drop 
would generate a huge impact current within the stator winding, and as well as the rotor due to the electromagnetic coupling between these two sides.

The LVRT of DFIG is accomplished through two methods at present, one is the control strategy based on adjusting the current convertor, and the other way is adding the hardware control circuit. The former method applies to a narrow-range voltage drop situation, when it comes to a serious fault, adding a Crowbar protective circuit is a better solution other than adjusting the current convertor due to its disappointing performance. The impedance of the Crowbar and its post-set time significantly influence the performance of the LVRT. The focus of this paper is on the steady state after the adjustment process.

The rotor is short-circuited and the current convertor on the generator side is locked when the Crowbar is attached. Under this circumstance, the DFIG is similar to the squirrel cage motor with the same short circuit current characteristics. Fig. 1 is the diagram of Crowbar.

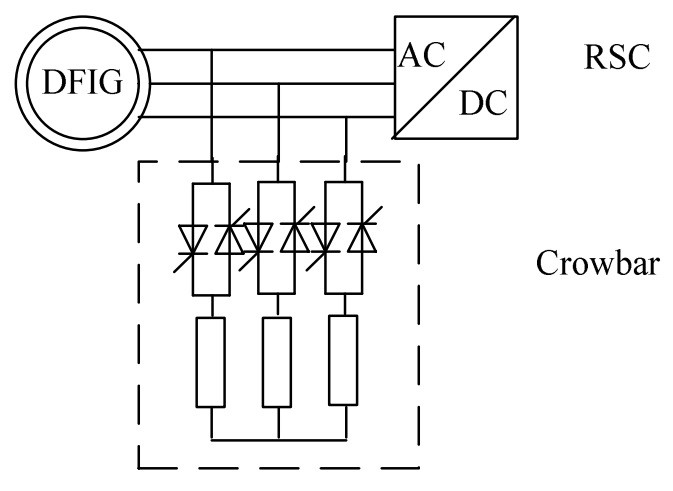

Fig. 1 The diagram of Crowbar

Neither the Crowbar nor the LVRT and the branch with the rotor current convertor are considered within the model when calculating under a slight fault (consider the impedance of the crowbar is zero). Thus, the positive and negative sequence equivalent impedance are shown in Fig. 2 and Fig. 3. the positive and negative sequence equivalent impedance are shown in equations (1).

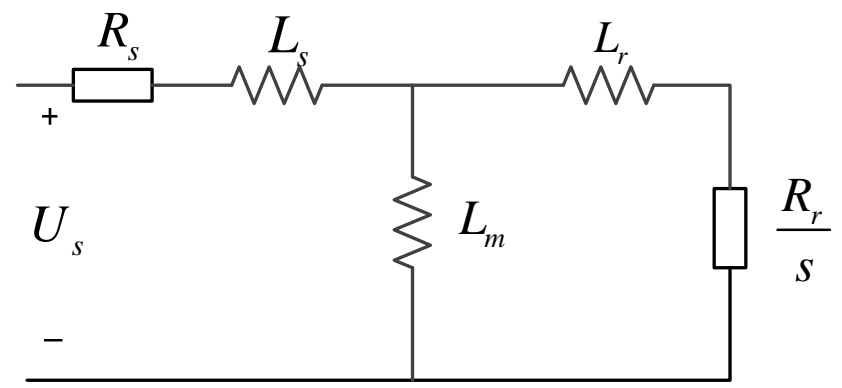

Fig. 2 The equivalent circuit of positive sequence 


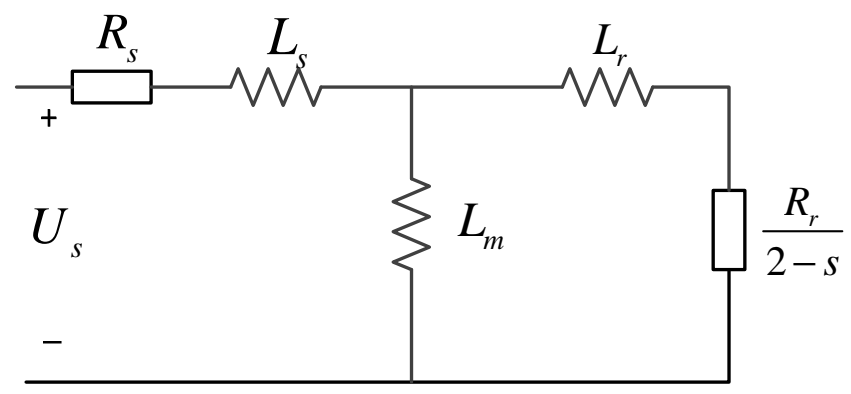

Fig. 3 The equivalent circuit of negative sequence

$$
\begin{aligned}
& Z_{1}=R_{\mathrm{s}}+j X_{\mathrm{s}}+j X_{\mathrm{m}} / /\left(j X_{\mathrm{r}}+\frac{R_{\mathrm{r}}}{s}\right) \\
& Z_{2}=R_{\mathrm{s}}+j X_{\mathrm{s}}+j X_{\mathrm{m}} / /\left(j X_{\mathrm{r}}+\frac{R_{\mathrm{r}}}{2-s}\right)
\end{aligned}
$$

The waveform of the angle-slip and the amplitude of the impedance could be obtained from the positive and negative sequence equivalent model and equations of the asynchronous generator. From which the significant difference between positive and negative sequence impedance could be observed. Therefore, it is not appropriate to use one model to calculate these two sequence.

Figure 4 illustrates the relations between positive or negative impedance and the slip (s), found with parameters on base values: generator parameters (p.u.): stator resistance $R_{s}=0.01$, stator leakage reactance $X_{s}=0.01$, excitation reactance $X_{m}=0.01$, rotor leakage reactance $X_{r}=0.1$ and rotor resistance $R_{r}=0.01$.
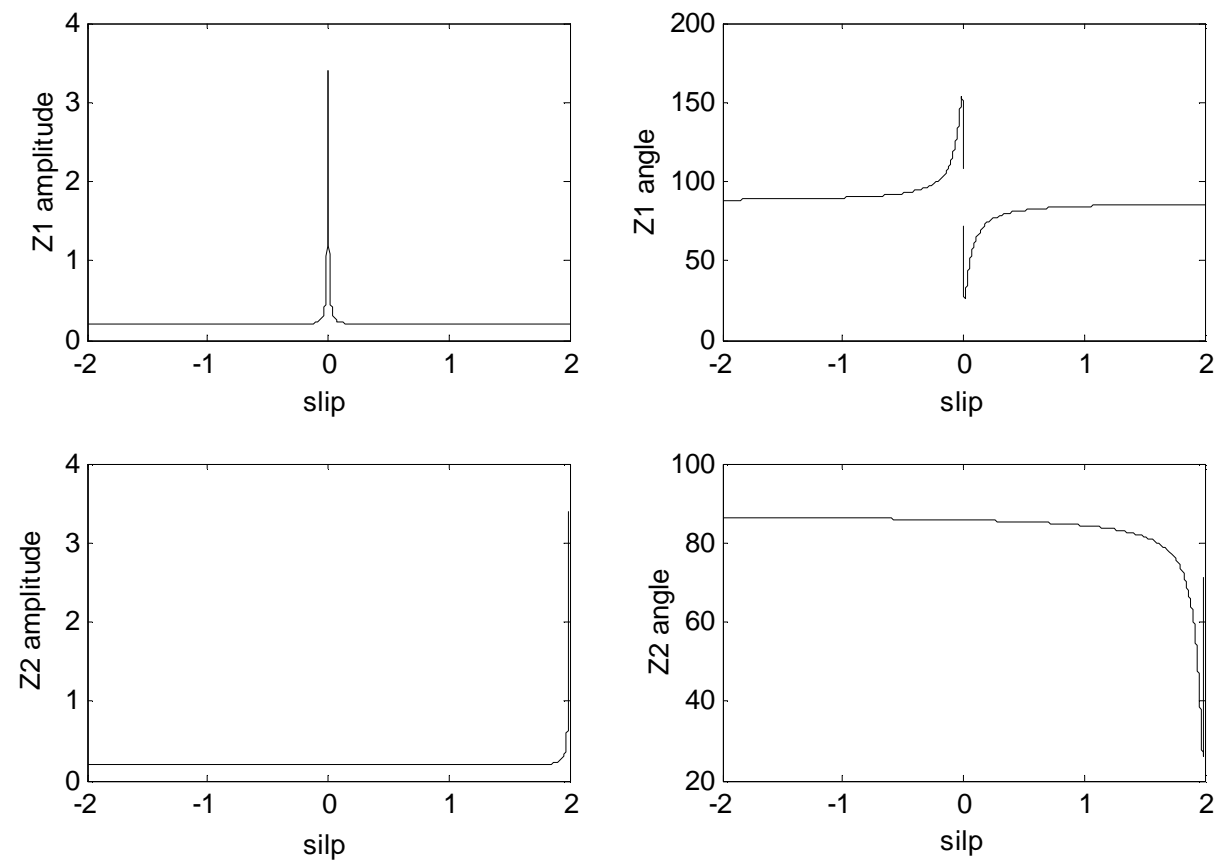

Fig. 4 The diagram of magnitude and angle 
During a sever fault, the crowbar resistance is about 30 40 times than stator resistance, thus, considering the influence of the crowbar resistance, the following two figures can be found with $R_{\text {Crowerbar }}=0.1$
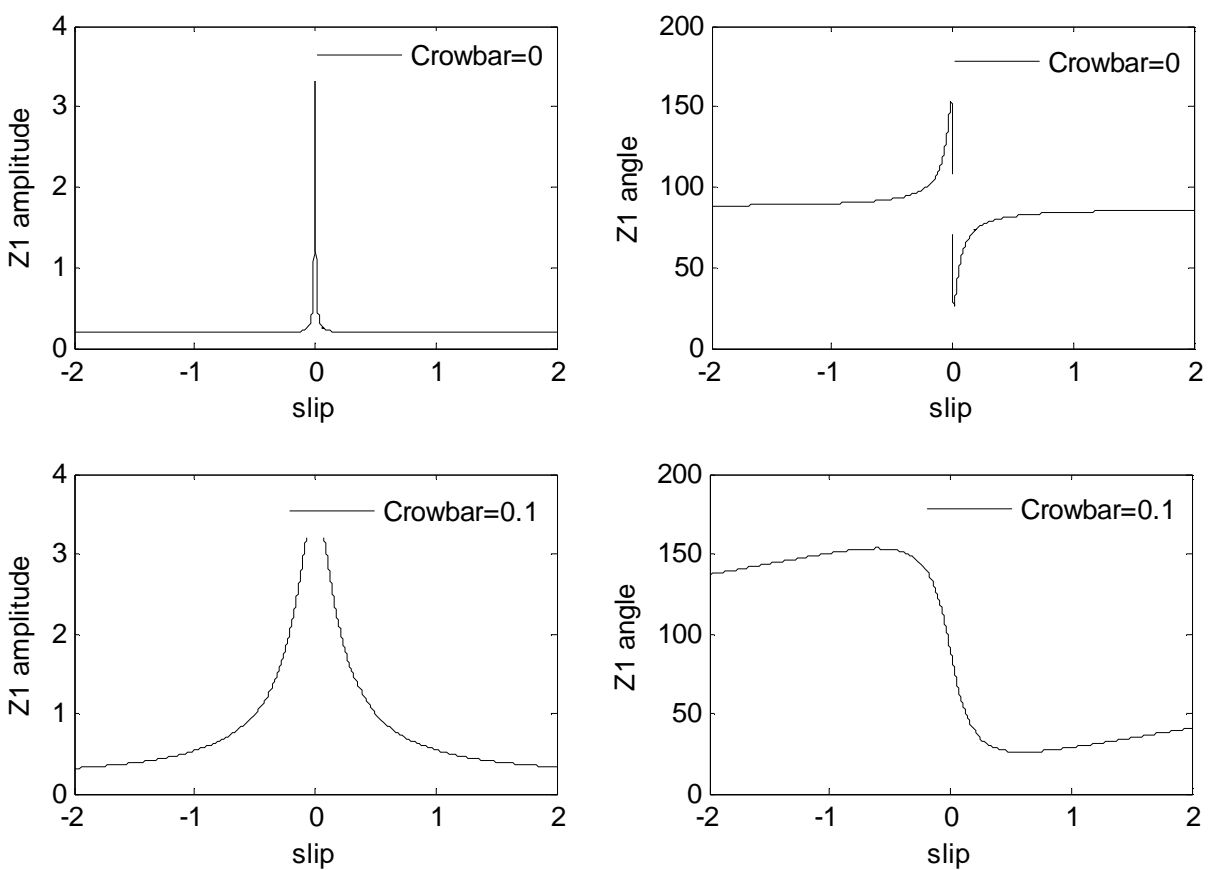

Fig. 5 The comparative graphs of positive sequence
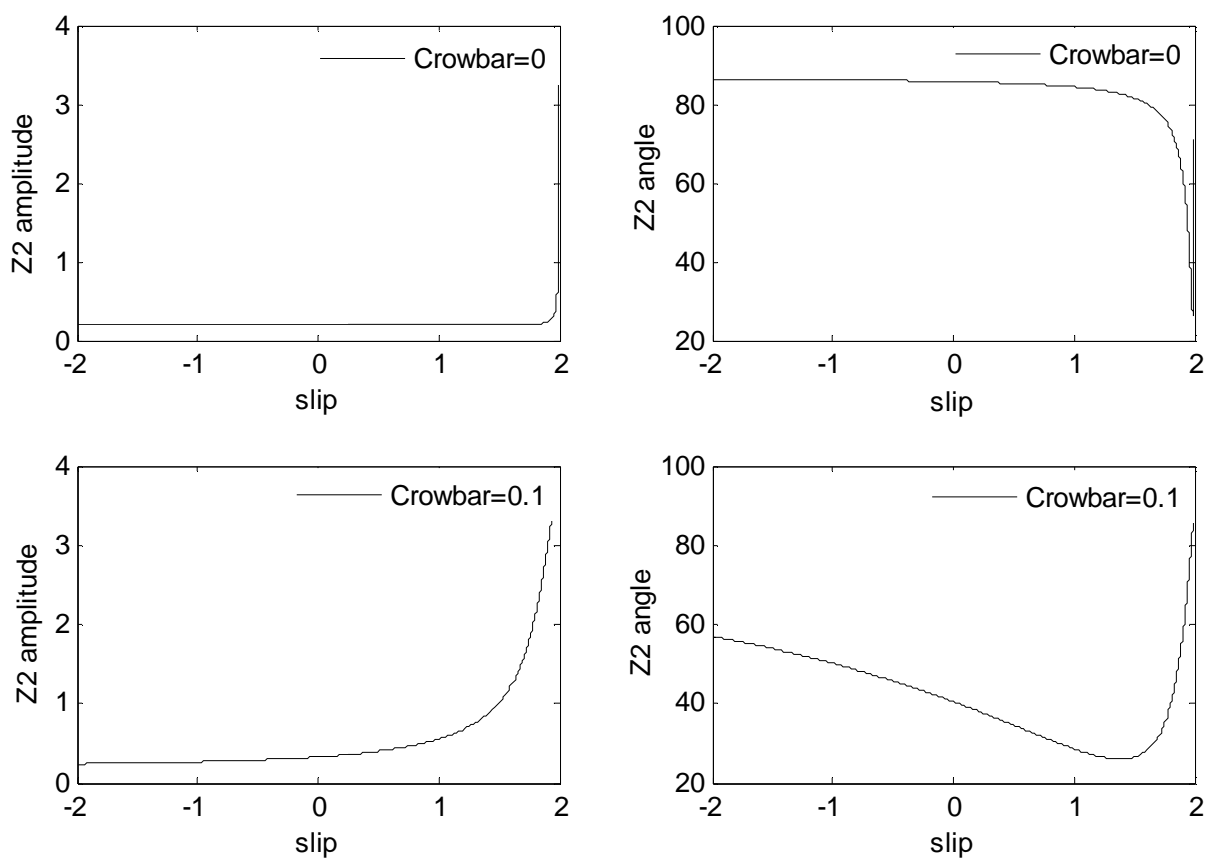

Fig. 6 The comparative graphs of negative sequence

Figure 5 , Figure 6 demonstrate the tremendous effect of the crowbar upon positive and negative impedance, which means that diverse wind farm models should be applied correspondingly to different fault levels. 
Thus, for different fault types, impedance calculation should be divided into two procedures to ensure the accuracy of calculation; first step is to calculate the model without the crowbar circuit, checking the satisfaction conditions for connecting the crowbar, secondly to calculate with the crowbar circuit connected if those conditions are satisfied.

The asynchronous generator is differing from the asynchronous motor. The rotors always accelerate after the generator recoil since the mechanical torque will be greater than the electromechanical torque when a symmetrical or asymmetrical fault occurs. Considering the rotating speed becomes twice the synchronous speed at the worst case, the positive impedance can be obtained from equation (2) with $S=-1$.

$$
\begin{aligned}
& Z_{1}=R_{\mathrm{s}}+j X_{\mathrm{s}}+j X_{\mathrm{m}} / /\left(j X_{\mathrm{r}}+\frac{R_{\mathrm{r}}+R_{\text {Crowbar }}}{-1}\right) \\
& Z_{2}=R_{\mathrm{s}}+j X_{\mathrm{s}}+j X_{\mathrm{m}} / /\left(j X_{\mathrm{r}}+\frac{R_{\mathrm{r}}+R_{\text {Crowbar }}}{3}\right)
\end{aligned}
$$

\section{Wind farm model}

Figure 7 demonstrates a typical structure of the wind farm. Each paralleled generation unit consists of a turbine and a package transformer in series. Figure 7 is the equivalent Model.

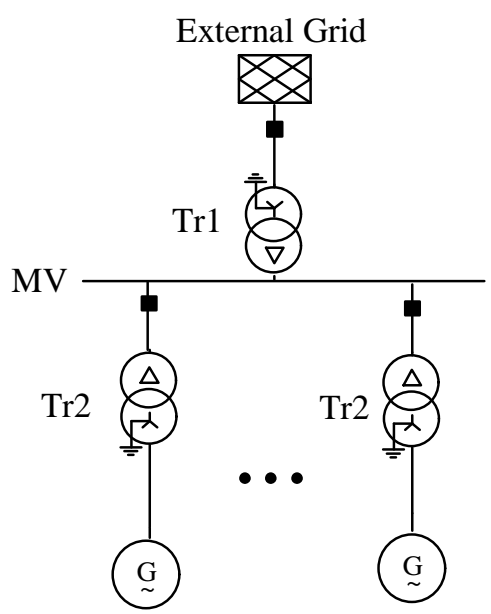

Fig. 7 The actual model of wind farm

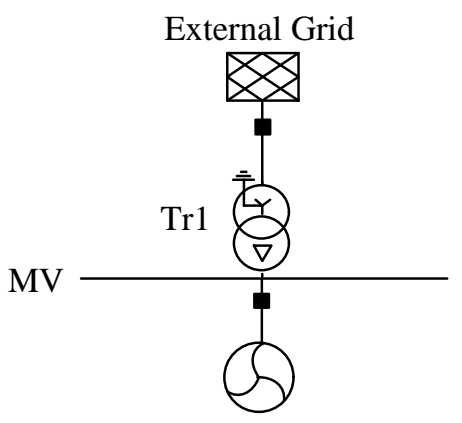

Fig. 8 The equivalent Model 
A fact that has been noticed while building the equivalent wind farm model is that the actual quantity of the wind turbine connected to the grid is not fixed. This paper use the maximum and minimum quantity of the wind turbine in actual situations as the corresponding operation mode of the wind farm model.

\section{Example}

Take the Xinjiang network as an example. Table 1, Table 2, Table 3, Table 4 are the example's parameter.

Table 1.The parameters of individual transformer

\begin{tabular}{lc}
\hline Parameter ( unit) & V alue \\
\hline $\begin{array}{l}\text { Rated voltage (kV) } \\
\text { Percentage of short circuit loss } \\
(\%)\end{array}$ & 10 \\
\hline
\end{tabular}

Table 2. The parameters of individual wind turbine

\begin{tabular}{lc}
\hline Parameter ( unit) & V alue \\
\hline Turbine number(max) & 24 \\
Turbine number(min) & 10 \\
Rated apparent power(K V A) & 1579 \\
Rated PF & $-0.9 \sim 0.9$ \\
Rated voltage (V ) & 690 \\
Single crowbar resistance(p.u.) & 0.1 \\
Single stator impedance (p.u.) & j0.1+0.01 \\
Single rotor impedance (p.u.) & j0.1+0.01 \\
Excitation impedance (p.u.) & $j 3.5$ \\
\hline
\end{tabular}

Table 3. The parameters of power system does not matter

\begin{tabular}{cc}
\hline Parameter (unit) & V alue \\
\hline $\begin{array}{c}\text { Positive impedance at max } \\
\text { mode (p.u.) }\end{array}$ & $3.0056+j 8.0589$ \\
$\begin{array}{c}\text { N egative impedance at max } \\
\text { mode (p.u.) }\end{array}$ & $3.0056+j 8.0589$ \\
$\begin{array}{c}\text { Positive impedance at min } \\
\text { mode (p.u.) }\end{array}$ & $3.0056+j 8.0589$ \\
$\begin{array}{c}\text { N egative impedance at min } \\
\text { mode (p.u.) }\end{array}$ & $3.0056+j 8.0589$ \\
\hline
\end{tabular}

Table 4 . The parameters of power system going wrong

\begin{tabular}{lc}
\hline Parameter (unit) & V alue \\
\hline $\begin{array}{c}\text { Positive impedance at max } \\
\text { mode (p.u.) }\end{array}$ & $19791+j 8.0299$ \\
$\begin{array}{c}\text { N egative impedance at } \\
\text { max mode (p.u.) }\end{array}$ & $13458+j 7.9877$ \\
$\begin{array}{c}\text { Positive impedance at min } \\
\text { mode (p.u.) }\end{array}$ & $4.7498+19.2717$ \\
$\begin{array}{c}\text { N egative impedance at } \\
\text { min mode (p.u.) }\end{array}$ & $3.2299+19.1704$ \\
\hline
\end{tabular}


Figure 9 illustrates an example of three-phase short circuit at the terminal of the turbine in Xinjiang Sarm wind farm. The contribution of the wind turbine is 1943 A.

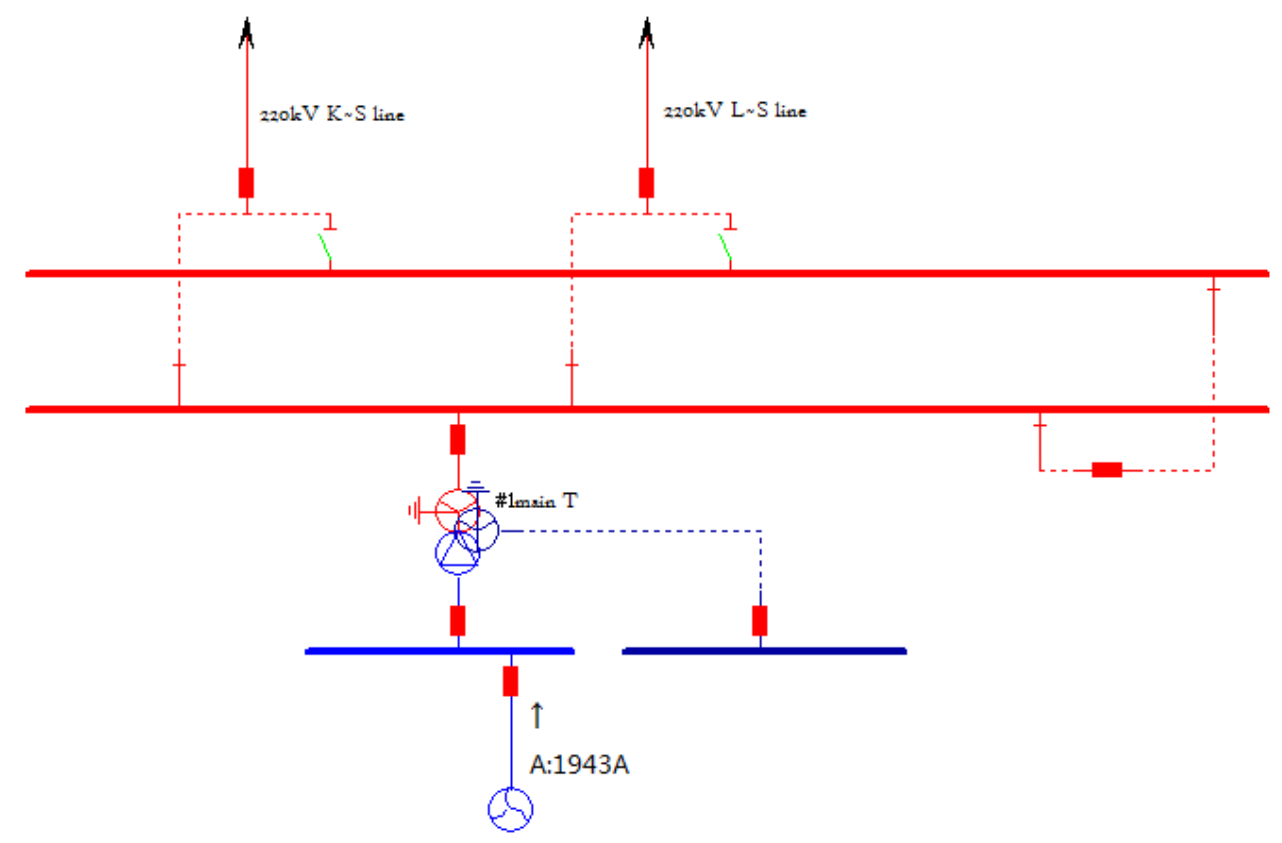

Fig. 9 The fault current provided by wind turbine

\section{Summary}

Numerous researches on on-grid wind turbine and wind farm has been carried out since nineteen nineties, and preliminary results has been achieved. The simulation of large-scale wind generation connecting to the grid, however, has been stalled because of the lack of appropriate equivalent models, making the correct assessment towards the influence of large-scale wind farms on the power network difficult. This paper illustrates the effect of wind farms on fault calculation and obtains an equivalent wind farm model through the research on DFIG. This achievement exerts a profound influence on the power system stabilization and the accuracy of protection setting calculation.

\section{References}

[1] WEN Yu-ling, CHAO Qin, TUERXUN Yibulayin, Impact of Interconnected Wind Farm on Power System Protection, Power System Technology, Vol.32, No.14, Jul.2008. In Chinese

[2] XIA Yebo, Analysis of the Impact of Interconnected Wind Farm on Power System Protection, Industry Technology, p31-31, 2015. In Chinese

[3] ZHANG Baohui, YIN Xianggen, Protection Principle of Power System, China Electric Power Press, Beijing, 2005. In Chinese

[4] HE Yangzan, WEN Zengyin, Analysis of Electric Power System (part 1), Huazhong University of Science and Technology (HUST) Press, Wuhan, 2010. In Chinese

[5]ZHENG Jianhua, Research on Control Technology of Double-fed Wind Power Generator System, Master Dissertation, Guangdong University of Technology, Guangdong, 2009. In Chinese 